\title{
APPLICATIONS OF INTEGRATED SAFETY ANALYSIS METHODOLOGY TO RELOAD SAFETY EVALUATION
}

\author{
CHANSU JANG* and KILSUP UM \\ Korea Nuclear Fuel \\ 1047 Daedeokdaero, Yuseong-gu, Daejeon, 305-353, Korea \\ *Corresponding author. E-mail : csjang@knfc.co.kr \\ Received October 19, 2009 \\ Accepted for Publication January 07, 2011
}

Korea Nuclear Fuel is developing the X-GEN fuel which shows high performance and robust reliability for the worldwide supply. However, the simplified code systems such as CESEC-III which were developed in 1970s are still used in the current Non-LOCA safety analysis of OPR1000 and APR1400 plants. Therefore, it is essential to secure an advanced safety analysis methodology to make the best use of the merits of X-GEN fuel. To accomplish this purpose, the integrated safety analysis methodology (iSAM), is developed by selecting the best-estimate thermal-hydraulic code RETRAN. iSAM possesses remarkable advantages, such as generality, integrity, and designer-friendly features. That is, iSAM can be applied to both OPR1000 and APR1400 plants and uses only one computer code, RETRAN, in the whole scope of the non-LOCA safety analyses. Also the iSAM adopts the unique and automatic initialization and run tool, automatic steady-state initialization and safety analysis tool (ASSIST), to enable unhandy designers to use the new design code RETRAN without difficulty. In this paper, a brief overview of the iSAM is given, and the results of applying the iSAM to typical non-LOCA transients being checked during the reload design are reported. The typical non-LOCA transients selected are the single control element assembly withdrawal (SCEAW) accident, the asymmetric steam generator transients (ASGT), the locked rotor (LR) accident, and bank CEA withdrawal (BCEAW) event. Comparison to current licensing results shows a close resemblance; thus, it reveals that the iSAM can be applied to the non-LOCA safety analysis of OPR1000 and APR1400 plants.

KEYWORDS : Non-LOCA Safety Analysis, Thermal-Hydraulic Analysis Code, Reload Design

\section{INTRODUCTION}

Korea Nuclear Fuel (KNF) has developed the integrated safety analysis methodology (iSAM) using the best-estimate thermal-hydraulic code RETRAN [1] for non-LOCA transient safety analysis since 2006 . The first objective of this project is to secure a safety analysis methodology required to allow the merits of the X-GEN fuel which KNF is developing to be fully realized. The second objective is to set up a general methodology to be applied to the licensing safety analyses of all the OPR 1000 and APR1400 plants. The third objective is to integrate the various computer codes used in non-LOCA transient safety analysis into one computer code, RETRAN. Finally, it aims to develop a designer-friendly methodology so that users who are unfamiliar with RETRAN code can use it easily in the non-LOCA safety analysis.

To verify the applicability of the iSAM to reload safety evaluation, most transients for safety analysis report (SAR) and for the core operating limit supervisory system/core protection calculator (COLSS/CPC) setpoint analysis have been analyzed and compared with the results from current safety analyses. The results show good agreement, and we conclude that the iSAM can be used in the licensing calculations for all OPR1000 and APR1400 plants.

In this paper, we present an overview of the iSAM and results of its application to typical transients. With respect to the COLSS/CPC setpoint analysis, the single control element assembly (CEA) withdrawal (SCEAW) accident and the asymmetric steam generator transients (ASGTs) are described. With respect to FSAR analysis, the bank CEA withdrawal (BCEAW) event and the locked rotor (LR) accident are described.

\section{OVERVIEW OF ISAM}

In the existing methodology, CESEC-III [2] computer code is used to simulate nuclear power plant system behavior during the non-LOCA transients of OPR1000 and APR1400 plants. This CESEC-III code comprises very simple calculation models and various constitutive components to compliment its simple logics. 
However, for the iSAM, RETRAN computer code is selected due to the benefits of the best-estimate thermalhydraulic analysis model. The standard nodal scheme for the iSAM is constructed similarly to that of CESEC-III code, which is familiar to most designers. However, there are some minor differences in the nodal scheme because of the discrepancy between two codes.

The RETRAN basedeck for the iSAM is automatically generated based on the standard nodal scheme by using the GUI-based RETRAN input generator (GRIG) program [3]. GRIG can generate the RETRAN input deck via the GUI from the plant database. Moreover, RETRAN input can be generated easily by drawing the nodes, junctions, and control blocks with GRIG.

In the iSAM, all non-LOCA transient analyses are performed by running the ASSIST [4] based on the GRIG-generated RETRAN basedeck together with transient specific input. The ASSIST has been developed to assist unhandy designers in analyzing various nonLOCA transients by using RETRAN code. The main function of ASSIST is to initialize all of the RETRAN input using the null-transient method. Typically, nonLOCA transients include the various initial conditions and control logic, which should be initialized using proper initial values. Therefore, ASSIST runs the RETRAN code to make every important parameter steady during the null-transient calculations. This process is very important in the control system, which needs accurate reference values. Through the ASSIST run, designers can generate ready-to-go RETRAN input, automatically set up designer specified initial transient conditions, and obtain designer-friendly formatted output. Figure 1 shows a schematic flow diagram of iSAM from input to output.

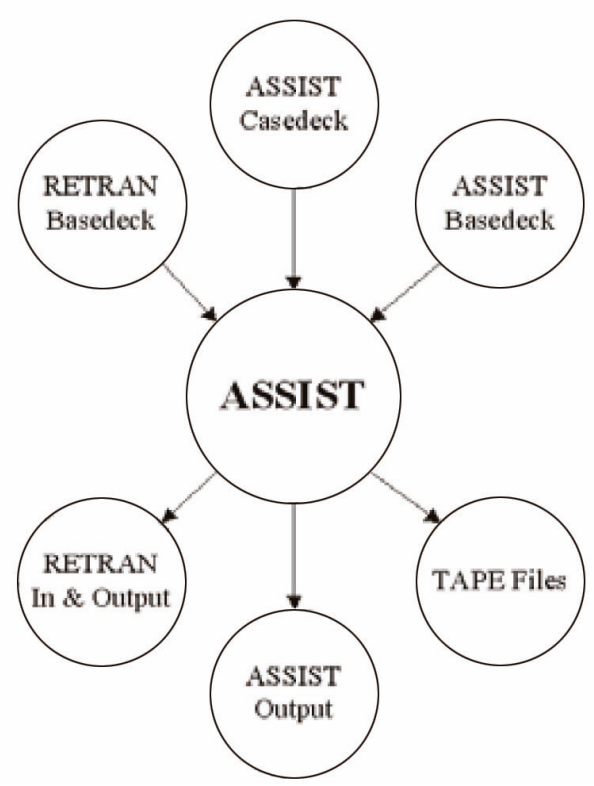

Fig. 1. Schematic Flow Diagram of iSAM

\section{APPLICATION RESULTS OF ISAM}

To validate the feasibility of iSAM, comparisons to the results of the licensing calculation have been performed in detail.

\subsection{Single CEA Withdrawal $[5,6]$}

An operator error could cause a single CEA withdrawal. This type of event results in an increase in core power, which is followed by increases in reactor coolant temperature and pressure. In addition, the withdrawal of a CEA produces a time dependent asymmetric redistribution of radial and axial core power distribution. These transient variations in core thermal parameters may result in a rapid approach to the specified acceptable fuel design limit (SAFDL) and could require protective action by the reactor protection system.

The purpose of this analysis is to calculate the required overpower margin (ROPM) to ensure that SAFDL is not violated by an SCEAW event. The SCEAW accident, which is a reactivity inserted transient, is analyzed at $95 \%, 65 \%, 50 \%, 20 \%$ and $0 \%$ of the design power. Thus, the applicability of iSAM and reactivity effects can be checked at each power level. In this paper, the results of $95 \%$ and $65 \%$ cases will be presented.

Table 1 shows the initial conditions used for the SCEAW accident analysis, and Table 2 shows the comparison results of ROPM to be maintained by the limiting conditions for operation (LCO) at $95 \%$ and $65 \%$

Table 1. Initial Conditions for SCEAW

\begin{tabular}{c|c|c}
\hline Parameters & $95 \%$ Power & $65 \%$ Power \\
\hline Core power, fraction & 0.95 & 0.65 \\
\hline Core inlet temperature, ${ }^{\circ} \mathrm{C}$ & 287.8 & 287.8 \\
\hline System pressure, $\mathrm{kg} / \mathrm{cm}^{2}$ & 158.2 & 158.2 \\
\hline Core flow rate, fraction & 0.95 & 0.95 \\
\hline Doppler temp. coefficient & Least negative & Least negative \\
\hline Moderator temp. coefficient & Most positive & Most positive \\
\hline Delayed neutron fraction & BOC & EOC \\
\hline Decay constants & BOC & EOC
\end{tabular}

Table 2. Comparison of the ROPM for SCEAW

\begin{tabular}{c|c|c}
\hline Power Level & CESEC-III & RETRAN \\
\hline $95 \%$ & 1.148 & 1.141 \\
\hline $65 \%$ & 1.348 & 1.350 \\
\hline
\end{tabular}


power levels. Figures 2 and 3 show comparisons of the normalized power and reactivity behavior, respectively, at $95 \%$ power. The results demonstrate that there is a little difference between iSAM and the current methodology.

\subsection{Asymmetric SG Transients [6]}

The objective of ASGT analysis is also to determine the ROPM that must be maintained. The following four

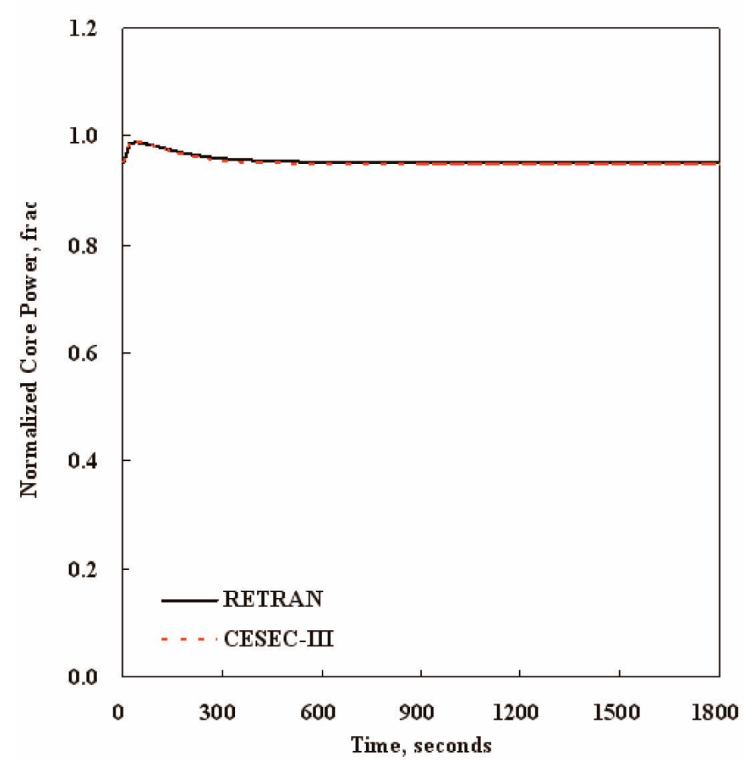

Fig. 2. Normalized Core Power vs. Time for SCEAW at 95\%

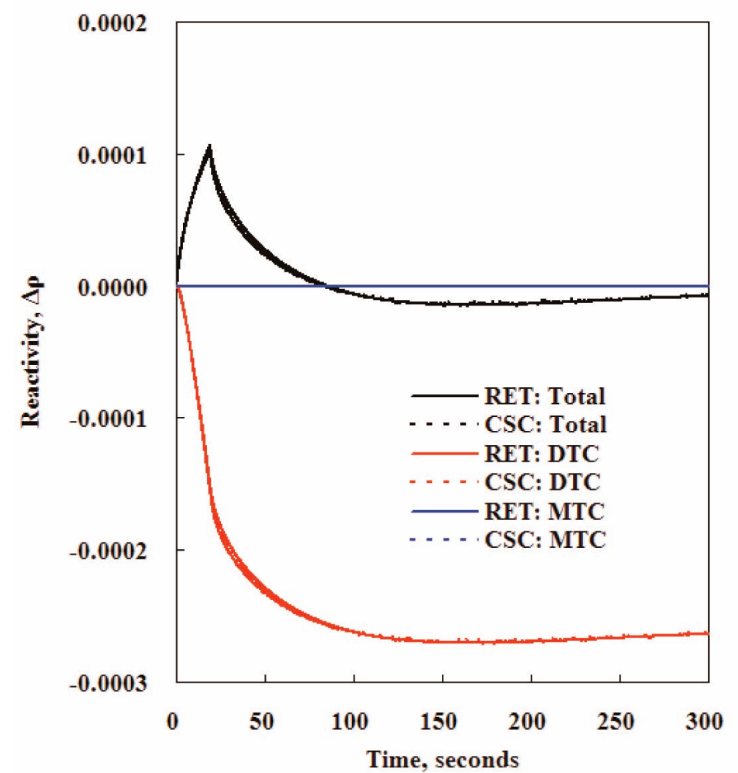

Fig. 3. Total Reactivity vs. Time at SCEAW at $95 \%$ scenarios cause asymmetric SG transients:

- Loss of load to one steam generator

- Loss of feed water to one steam generator

- Excess feed water to one steam generator

- Excess load to one steam generator

First, the sensitivity runs to determine the limiting ASGT scenario are performed. To maximize the asymmetry due to the isolation of one steam generator, no mixing in the core inlet plenum is assumed. Due to the asymmetric temperature profile, the core radial power distribution shifts toward the cold side if the moderator temperature coefficient is negative. This shift of core radial power distribution causes the radial peaking factor to increase, which yields a decrease in departure from nucleate boiling ratio (DNBR). The sensitivity results with respect to the core temperature difference between the cold and hot sides demonstrate that the loss of load to one steam generator scenario is the most limiting transient as shown in Table 3.

In the loss of load to one SG scenario, the reactor is initially operating at full power conditions and nominal steam generator water level and pressure. A single main steamline isolation valve (MSIV) quickly closes within 0.1 seconds, which isolates the steam flow from one steam generator. Upon the loss of load to one steam generator, its pressure and temperature begin to increase. Also, the isolated steam generator water level rapidly drops as the increasing pressure collapses steam bubbles in the liquid inventory. The pressure continues to increase until the main steam safety valves open. The pressure of the other steam generator remains steady or drops depending on the operation mode of the turbine generator control system.

Asymmetry in the core inlet temperature distribution occurs when the core inlet temperature in the primary coolant loop associated with the isolated steam generator increases due to a reduction in the primary-to-secondary heat transfer rate caused by the termination of the steam flow from the isolated steam generator. The core inlet temperature in the primary coolant loop associated with the unaffected steam generator decreases due to the cooling action of the unaffected steam generator which picks up the load lost by the isolated steam generator.

Because of the presence of the negative moderator temperature coefficient and the Doppler temperature coefficient, the radial power shifts toward the cold side

Table 3. Results of Temperature Difference for ASGT

\begin{tabular}{c|c|c}
\hline Transient & CESEC-III & RETRAN \\
\hline Loss of Load & $17.47^{\circ} \mathrm{C}$ & $17.31^{\circ} \mathrm{C}$ \\
\hline Loss of or Excess FW & $0.81^{\circ} \mathrm{C}$ & $0.82^{\circ} \mathrm{C}$ \\
\hline Excess Load & $0.35^{\circ} \mathrm{C}$ & $0.35^{\circ} \mathrm{C}$ \\
\hline
\end{tabular}


of the core, where no mixing of the core inlet flow is assumed. This radial peaking factor increase leads to an increase in the peak linear heat rate and a decrease in DNBR, which is partially mitigated by the decreasing coolant temperature at the peak location. After some time, the power on the hot side of the core decreases due to the negative reactivity feedback effects. The doppler reactivity feedback effect re-stabilizes and flattens the radial core power redistribution.

For the limiting transient (loss of load), the plant behavior is simulated at $100 \%, 70 \%$, and $50 \%$ power levels, respectively. Table 4 shows the initial conditions used for the $100 \%$ power case.

Figure 4 shows the SG pressures vs. time, where the upper lines indicate the pressures of the isolated SG and solid lines represent the iSAM results. Due to the SG isolation, the pressures in the affected SG increase until

Table 4. Initial Conditions for ASGT at 100\% Power

\begin{tabular}{c|c}
\hline Parameters & Values \\
\hline Core power, fraction of nominal & 1.02 \\
\hline Core inlet temperature, ${ }^{\circ} \mathrm{C}$ & 295.8 \\
\hline System pressure, $\mathrm{kg} / \mathrm{cm}^{2}$ & 158.2 \\
\hline Core flow rate, fraction of nominal & 1.0 \\
\hline Doppler temperature coefficient & Least negative \\
\hline Moderator temperature coefficient & Most negative \\
\hline
\end{tabular}

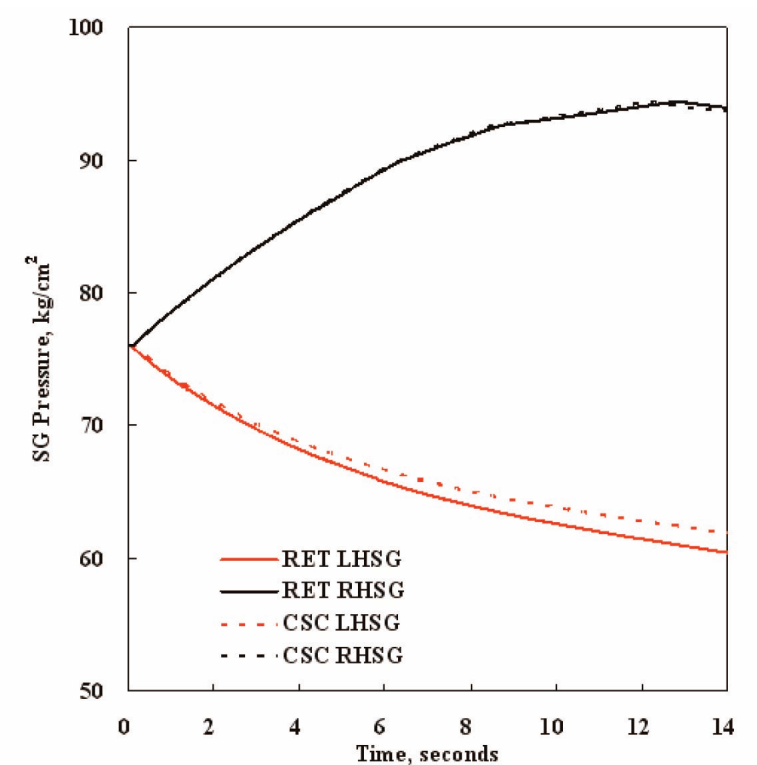

Fig. 4. SG Pressures vs. Time for ASGT at $100 \%$ Power the main steam safety valves open. Figure 5 shows the core coolant temperatures vs. time, where the split core coolant temperatures are found due to the asymmetric behavior of the steam generators.

Figure 6 shows the DNBR vs. time, where the RETRAN is slightly lower than CESEC-III code. Table 5 shows comparison results of the required overpower margin. Similar results are found for iSAM and the current methodology.

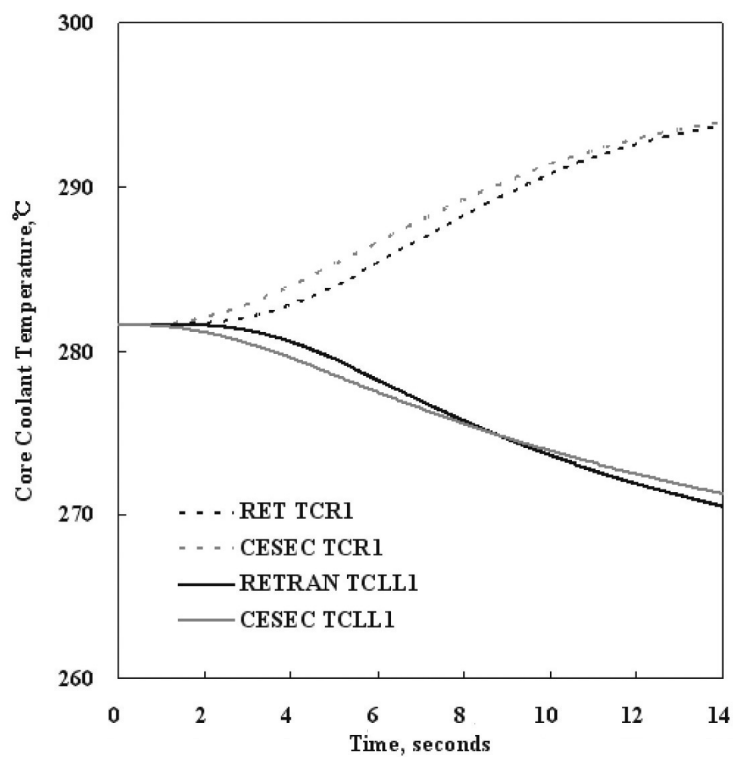

Fig. 5. Core Coolant Temperatures vs. Time for ASGT at $100 \%$ Power

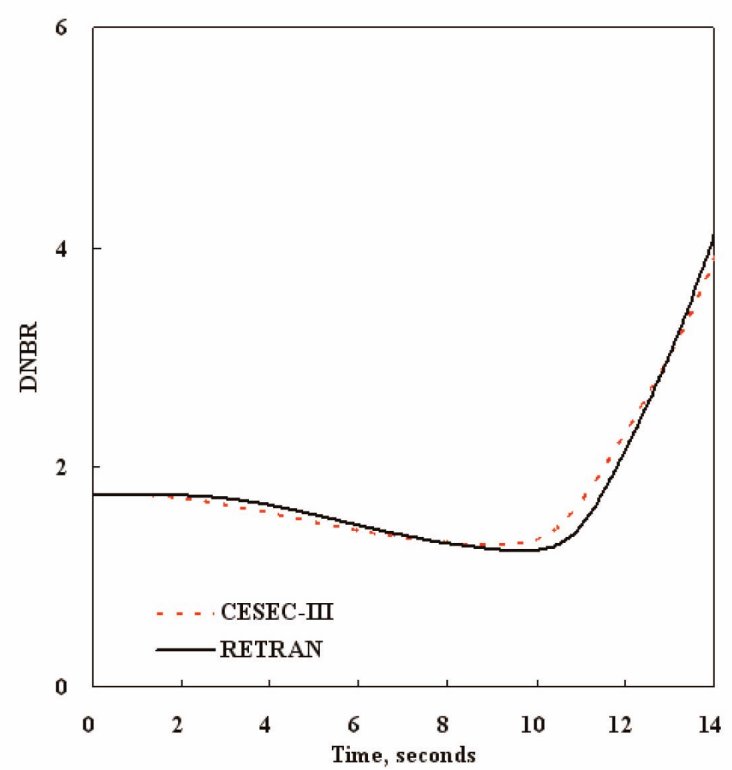

Fig. 6. DNBR vs. Time for ASGT at $100 \%$ Power 


\subsection{Locked Rotor [5]}

A locked rotor can be caused by seizure of the upper or lower thrust-journal bearings. Loss of offsite power (LOOP) subsequent to turbine-generator trip may be caused by a complete loss of the external electrical grid triggered by the turbine-generator trip. Due to LOOP, a plant will experience a simultaneous loss of feedwater flow, condenser inoperability, and a coastdown of all reactor coolant pumps.

For this type of accident, major parameters of concern are the minimum hot channel DNBR and the peak pressure in the reactor coolant system. The minimum hot channel DNBR establishes whether SAFDL has been violated and thus, whether fuel damage could be anticipated. For a single reactor coolant pump rotor seizure event, the minimum DNBR occurs during the first one to four seconds of the transient, and the reactor is tripped by the reactor protection system on low hot leg coolant flow.

The current methodology uses the HERMITE [7] code to simulate the locked rotor transients with respect to the DNBR and the CESEC-III code to calculate the maximum reactor coolant system and secondary pressures.

Tables 6 and 7 show the initial conditions for the evaluation of minimum DNBR and for the estimation of the maximum primary and secondary pressures, respectively.

Table 5. Comparison of ROPM for ASGT

\begin{tabular}{c|c|c}
\hline Power Level $(\%)$ & CESEC-III & RETRAN \\
\hline 100 & 1.0553 & 1.0507 \\
\hline 70 & 1.1139 & 1.1198 \\
\hline 50 & 1.1254 & 1.1538 \\
\hline
\end{tabular}

Table 6. Initial Conditions for LR Minimum DNBR Calculation

\begin{tabular}{c|c}
\hline Parameters & Values \\
\hline Core power, fraction of nominal & 1.02 \\
\hline Core inlet temperature, ${ }^{\circ} \mathrm{C}$ & 293.3 \\
\hline System pressure, $\mathrm{kg} / \mathrm{cm}^{2}$ & 163.5 \\
\hline Core flow rate, fraction of nominal & 0.95 \\
\hline Doppler temperature coefficient & Least negative \\
\hline Moderator temperature coefficient & Most positive \\
\hline Hot channel flow factor & 0.6 \\
\hline Axial shape index & +0.3 \\
\hline Radial peaking factor & 1.8416 \\
\hline
\end{tabular}

HERMITE code can account for changes in the axial power distribution with the reactivity changes because it is a 3-dimensional physics code. Because the RETRAN code adopts point kinetics, RETRAN cannot detect changes in the axial power distribution. Therefore, the most limiting axial power shape should be used. In this calculation, the bottom-skewed shape is used. Figure 7 show the scram curves used in the DNBR calculation. In the legend, "Generic" means the generic scram curve, which is the limiting curve used in the safety analysis. "HERMITE" means the scram curve generated by HERMITE code.

The two kinds of scram curves shown in Figure 7 are studied to validate the applicability of the RETRAN model. In one case, the scram curve is generated by HERMITE code (referred as "RET/HER"). In the other case, the generic scram curve is used for the design of a

Table 7. Initial Conditions for LR Peak Pressure Calculation

\begin{tabular}{c|c}
\hline Parameters & Values \\
\hline Core power, fraction of nominal & 1.0302 \\
\hline Core inlet temperature, ${ }^{\circ} \mathrm{C}$ & 298.9 \\
\hline System pressure, $\mathrm{kg} / \mathrm{cm}^{2}$ & 163.5 \\
\hline Core flow rate, fraction of nominal & 0.95 \\
\hline Doppler temperature coefficient & Least negative \\
\hline Moderator temperature coefficient & Most positive \\
\hline Wall heat model & Included \\
\hline
\end{tabular}



Fig. 7. Scram Curves Used for LR DNBR Case 
nuclear power plant (referred as "RET/GEN"). Figure 8 shows the normalized average heat flux in the hot channel. After the scram rods begin to drop, the trend of nuclear power depends on the reactor scram curve used. The DNBR trend is shown in Figure 9, and the calculated minimum DNBR is shown in Table 8. The generic scream curve, which is used in the RETRAN model, shows a somewhat lower DNBR value.

The results of peak pressure shown in Table 9 and Figure 10 demonstrate that there is good agreement between the CESEC-III and RETRAN codes. RETRAN

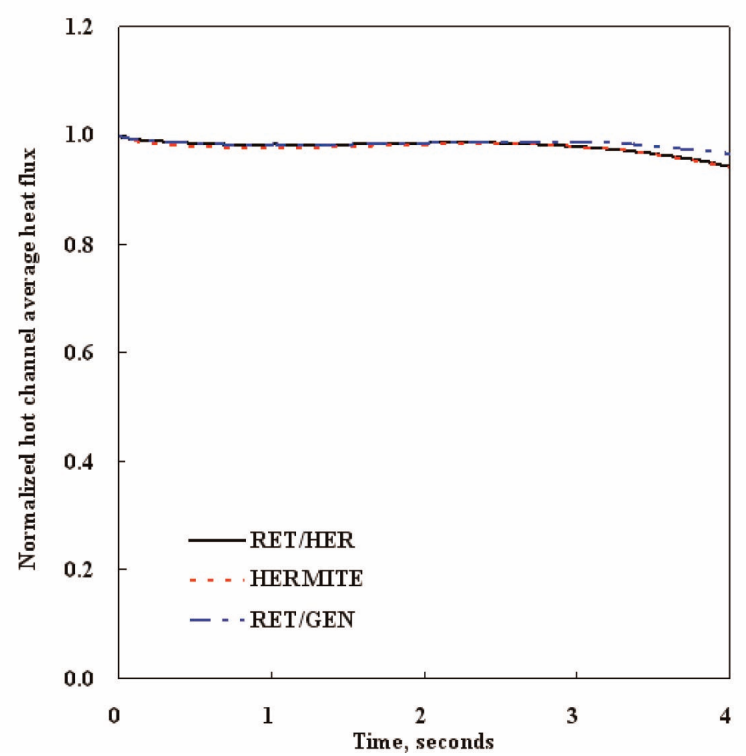

Fig. 8. Hot Channel Average Heat Flux for LR DNBR Case

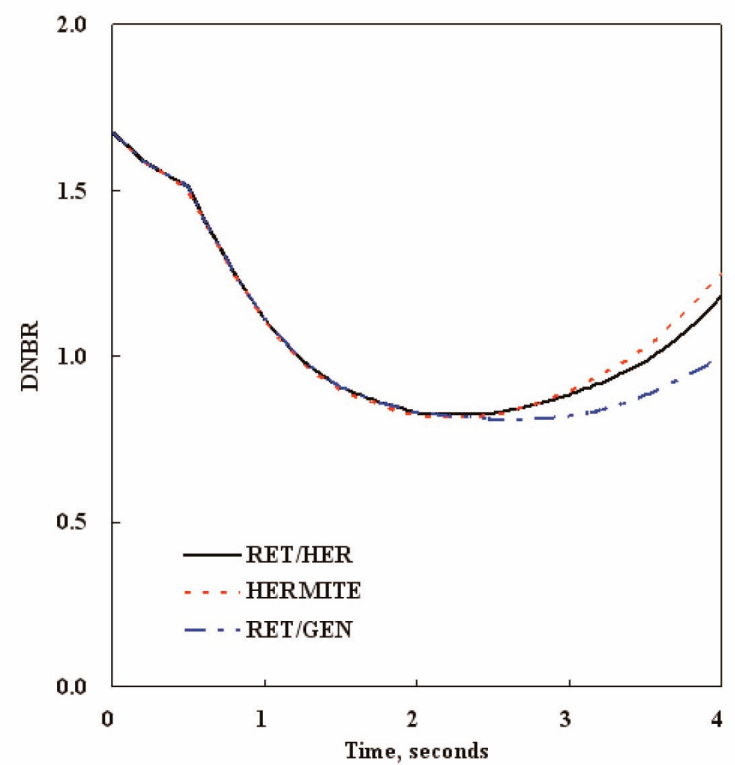

Fig. 9. DNBR vs. Time for LR code is expected to be slightly higher than CESEC-III code, but the difference is very small.

\subsection{Bank CEA Withdrawal (BCEAW)}

An uncontrolled sequential withdrawal of CEAs is assumed to occur as a result of a single failure in the CEDMCS (Control Element Drive Mechanism Control System), the reactor regulating system, or as a result of operator error.

A BCEAW event must be analyzed at several power levels, such as full power operating conditions, lower power conditions, and subcritical conditions.

A BCEAW event initiated under full power operating conditions results in a small rate of positive reactivity

Table 8. Results of Minimum DNBR for LR

\begin{tabular}{c|c}
\hline Cases & Min. DNBR \\
\hline RET/HER & 0.8227 \\
\hline HERMITE & 0.8134 \\
\hline RET/GEN & 0.8076 \\
\hline
\end{tabular}

Table 9. Results of Peak Pressure for LR

\begin{tabular}{c|c}
\hline Cases & Peak RCS Pressure, $\mathrm{kg} / \mathrm{cm}^{2}$ \\
\hline CESEC-III & 182.3 \\
\hline RETRAN & 182.4 \\
\hline
\end{tabular}



Fig. 10. Max. RCS Pressure vs. Time for LR 
addition since the lead bank (normally a low worth bank) is inserted only $28 \%$. This small positive reactivity addition, however, causes the core power, core average heat flux, and reactor coolant system temperature and pressure to rise and the DNB and linear heat rate margin to decrease. The pressure increase activates pressurizer sprays which mitigate the pressure rise.

The BCEAW also causes the axial power distribution to shift to the top of the core. The associated increase in the axial peak is compensated by a corresponding decrease in the integrated radial peaking factor. The magnitude of the 3-dimensional peak change depends primarily on the initial CEA configuration and the initial axial power distribution.

The BCEAW also causes the neutron flux power measured by the ex-core detectors to be de-calibrated due to CEA motion (i.e., rod shadowing effects). This decalibration of ex-core detectors, however, is partially compensated by reduced neutron attenuation arising from moderator density changes (i.e., temperature shadowing effects).

As the core power and heat flux increase, a reactor trip on CPC or high power trip may occur to terminate the event depending on the initial operating conditions and the rate of reactivity addition. If a trip occurs, the CEAs drop into the core and insert negative reactivity which terminates further thermal margin degradation. If no trip occurs and corrective action is not taken by the operator, the CEAs fully withdraw and the nuclear steam supply system (NSSS) achieves new steady state equilibrium with higher power, temperatures, and peak linear heat rate as well as a lower hot channel DNBR value.

A BCEAW event initiated at lower power levels will exhibit similar trends as the full power BCEAW, except that the rate of reactivity addition and margin degradation will be faster due to the greater insertion of CEAs allowed by the power-dependent insertion limit (PDIL) at lower power levels. The rate and magnitude of the power, temperature, heat flux, and pressure increase are therefore greater due to the greater reactivity addition. At hot zero power (including subcritical conditions), the BCEAW can result in a significant power "spike". Although the heat flux follows the rise in fission power, the magnitude of the heat flux increase is limited by the fuel time constant. The event is terminated by the variable overpower trip (VOPT), which limits the increase in core power, heat flux, primary coolant temperatures, and pressure.

As the BCEAW is classified as an anticipated operational occurrence, the objective of this analysis is to show that the SAFDL on DNBR and local power density would not be exceeded for a BCEAW from subcritical, low, and full power conditions. Additionally, primary and secondary pressures should be lower than the design criteria.

The initial conditions of BCEAW under the full power, low power, and subcritical conditions are given in Tables 10,11 , and 12, respectively. Figures 11,12 , and 13 show the core power under full power, low power, and subcritical conditions, respectively.

As seen in Figure 11, the location of peak power is different for RETRAN and CESEC codes. This phenomenon is due to the differences in the Doppler feedback calculation. Even though the location of peak power is different, the amount of peak power is similar. The trends of core power except for the full power case are the same.

Table 10. Initial Conditions for BCEAW at Full Power

\begin{tabular}{c|c}
\hline Parameters & Values \\
\hline Core power, MWt & 2871.3 \\
\hline Core inlet temperature, ${ }^{\circ} \mathrm{C}$ & 298.9 \\
\hline System pressure, $\mathrm{kg} / \mathrm{cm}^{2}$ & 140.6 \\
\hline Core flow rate, fraction of nominal & 0.95 \\
\hline Doppler temperature coefficient & Least negative \\
\hline Moderator temperature coefficient & Most positive \\
\hline Reactivity insertion, $\mathrm{pcm} / \mathrm{sec}$ & 4.1 \\
\hline
\end{tabular}

Table 11. Initial Conditions for BCEAW at Low Power

\begin{tabular}{c|c}
\hline Parameters & Values \\
\hline Core power, MWt & 0.02815 \\
\hline Core inlet temperature, ${ }^{\circ} \mathrm{C}$ & 300.0 \\
\hline System pressure, $\mathrm{kg} / \mathrm{cm}^{2}$ & 140.6 \\
\hline Core flow rate, fraction of nominal & 0.95 \\
\hline Doppler temperature coefficient & Least negative \\
\hline Moderator temperature coefficient & Most positive \\
\hline Reactivity insertion, pcm $/ \mathrm{sec}$ & 11.7 \\
\hline
\end{tabular}

Table 12. Initial Conditions for BCEAW at Subcritical

\begin{tabular}{c|c}
\hline Parameters & Values \\
\hline Core power, $\mathrm{MWt}$ & $5.45 \times 10^{-8}$ \\
\hline Core inlet temperature, ${ }^{\circ} \mathrm{C}$ & 300.0 \\
\hline System pressure, $\mathrm{kg} / \mathrm{cm}^{2}$ & 126.6 \\
\hline Core flow rate, fraction of nominal & 0.95 \\
\hline Doppler temperature coefficient & Least negative \\
\hline Moderator temperature coefficient & Most positive \\
\hline Reactivity insertion, pcm/sec & 24.45 \\
\hline
\end{tabular}




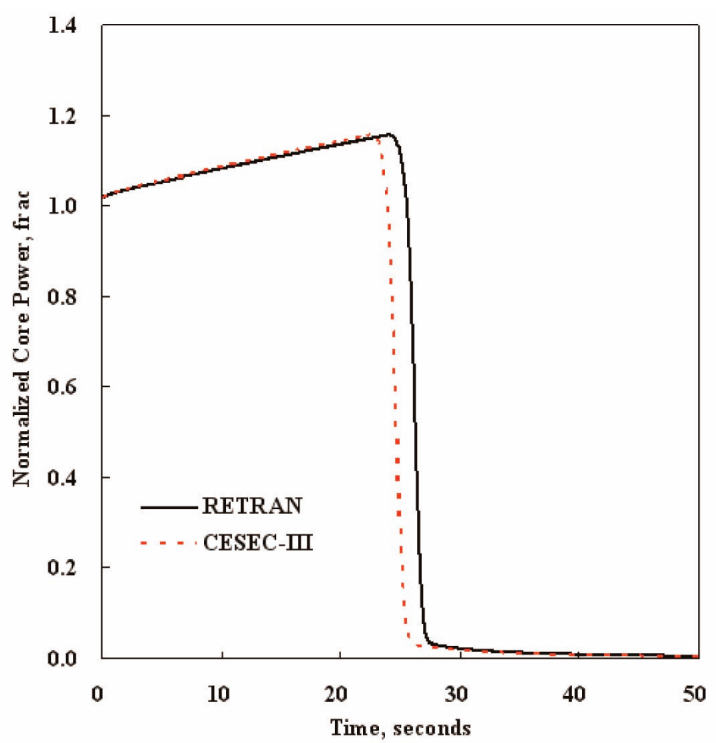

Fig. 11. Core Power vs. Time for BCEAW at Full Power



Fig. 12.Core Power vs. Time for BCEAW at Low Power

\section{CONCLUSIONS}

A designer-friendly methodology, the integrated safety analysis methodology (iSAM) based on RETRAN computer code was developed to fully utilize the advantages of X-GEN fuel. Most types of non-LOCA transients were analyzed and compared to the current design results to validate the applicability of the proposed method to reload safety evaluation. In this paper, four

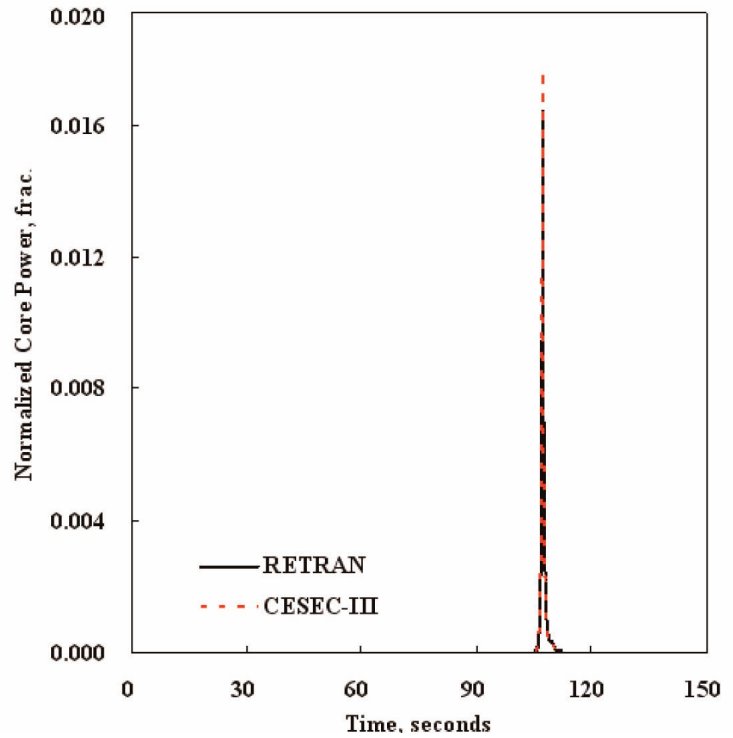

Fig. 13. Core Power vs. Time for BCEAW at Subcritical

types of accidents are presented. The comparison results show that there is close resemblance between the iSAM and the current methodology. Thus, we conclude that the iSAM can be applied in reload safety evaluation and licensing calculations for all OPR1000 and APR1400 plants.

\section{REFERENCES}

[1] "RETRAN-3D - A Program for Transient ThermalHydraulic Analysis of Complex Fluid Flow Systems," NP7450 (1996).

[2] "CESEC - Digital simulation of a combustion engineering nuclear steam supply system," Proprietary Information, (1981).

[ 3 ] G. J. Lee, S. H. Hwang, S. J. Hong, B. C. Lee., C. S. Jang and K. S. Um, "Conceptual Design of GRIG (GUI Based RETRAN Input Generator)," Transactions of the Korean Nuclear Society Spring Meeting, Jeju, Korea, May 10-11, 2007.

[4] C. S. Jang and S. J. Cho, "Automatic Steady-State Initialization and Safety Analysis Tool," RETRAN/VIPRE User Group Meeting, Palo Alto, USA, May 12, 2009.

[ 5 ] C. S. Jang, K. S. Um , J. D., Choi, "Development of the Advanced Non-LOCA Analysis Methodology for Licensing," Transactions of the Korean Nuclear Society Spring Meeting, Gyeongju, Korea, May 29-30, 2008.

[6] C. S. Jang and K. S. Um, "Applications of Innovative Safety Analysis Methodology (iSAM) to Reload Safety Evaluation," Transactions of the Korean Nuclear Society Spring Meeting, Jeju, Korea, May 22, 2009.

[ 7 ] "HERMITE, A Multi-Dimensional Space-Time Kinetics Code for PWR Transients," Proprietary Information, (1976). 